\title{
Selectivity and efficiency of pyrene attachment to alkanes induced by broadband $\mathrm{X}$-rays
}

\author{
GERALD O. BROWN ${ }^{1}$, NOEL A. GUARDALA ${ }^{2}$, JACK L. PRICE ${ }^{2}$ and RICHARD G. WEISS ${ }^{1}$ \\ ${ }^{1}$ Department of Chemistry, Georgetown University, Washington, DC 20057-1227 USA \\ ${ }^{2}$ Naval Surface Warfare Center, Carderock Division, 9500 MacArthur Boulevard \\ West Bethesda, MD 20817 USA
}

Manuscript received on December 20, 2002; accepted for publication on December 27, 2002; contributed by RICHARD G. WEISs*

\begin{abstract}
Bombardment of pyrene-doped $n$-heneicosane $\left(\mathrm{C}_{21} \mathrm{H}_{44}\right)$ in its orthorhombic solid phase with $<1.3>\mathrm{MeV}$ broadband X-rays results in the formation of both mono- and di-heneicosylpyrenes, whereas the same dose in liquid cyclohexane yields only monosubstituted pyrene. In both cases, the reaction efficiency decreases as pyrene concentration is increased from $10^{-5}$ to $10^{-2} \mathrm{M}$. Qualitatively, the overall attachment efficiency is higher in orthorhombic n-heneicosane than in liquid cyclohexane, but the selectivity of attachment is greater in cyclohexane. Differences between these results and those from irradiations of the same samples with eV range photons are discussed.
\end{abstract}

Key words: broadband x-rays, pyrene, cyclohexane, heneicosane.

\section{INTRODUCTION}

The misconception that pyrene (PyH), a polycyclic aromatic hydrocarbon, is inert when irradiated with $\mathrm{UV}$ (eV range) photons in saturated hydrocarbon media has persisted widely despite several reports to the contrary (Lamotte et al. 1985, 1987, 1991). Irradiations in solid and liquid alkane phases produce 1-alkylpyrenes in addition to other photoproducts whose number and type depend on photon wavelength. Thus, $248 \mathrm{~nm}$ radiation yields 1-and 4alkylpyrenes (via two-photon processes) whereas $185 \mathrm{~nm}$ radiation leads to alkylpyrenes and dihydropyrene photoproducts (via one-photon processes).

More recently, we have found that pyrene,

*Foreign Member of Academia Brasileira de Ciências Correspondence to: Richard G. Weiss

E-mail: weissr@georgetown.edu when doped in films and irradiated with $>300 \mathrm{~nm}$ radiation (Naciri and Weiss 1989, Luo et al. 2002, Brown et al. 2002c, Yamaki et al. 2002), can be covalently attached to chains of polyethylene and other polymers. In an effort to determine the sites within the polymer matrices most likely to lead to attachment, the consequences of irradiations of pyrene in a series of n-alkanes and an alkene were examined while monitoring the influences of radiation wavelength, solvent phase, pyrene concentration, and alkane chain length on the efficiency and selectivity of attachment (Zimerman and Weiss 1999). It was determined that pyrene molecules reside and react preferentially at interfaces between lamellae in solid phases of long-chained n-alkanes and that the photochemistry in the solid phases can be very selective when the radiation wavelength is $>300$ $\mathrm{nm}$ and the alkane chain contains at least 21 carbon 
atoms; only one photoproduct, 1-n-alkylpyrene, was detected in these cases.

Recently, we have demonstrated that bombardment of pyrene-doped polyethylene films with $\mathrm{MeV}$ range charged particles (electrons, protons, and alpha particles) results in the formation of both monoand di-substituted pyrenes (i.e., pyrene molecules attached to one or two polyethylene chains) (Brown et al. submitted). By contrast, only monosubstituted products are detected when the same samples were exposed to $>300 \mathrm{~nm}$ radiation (Brown et al. 2002 $a, b, c)$.

Few studies have compared the modes of energy deposition by $\mathrm{eV}$ photons and $\mathrm{MeV}$ particles ( $\gamma$-rays, electrons, protons, etc.) in organic media (Caldwell et al. 1966, Hammond et al. 1968, Penner et al. 1970, Penner and Hammond 1971). Here, we examine the effects of exposing pyrene in liquid phase cyclohexane and solid (orthorhombic) phase n-heneicosane $\left(\mathbf{C 2 1} ; \mathrm{C}_{21} \mathrm{H}_{44}\right)$ to $<1.3>\mathrm{MeV}$ broadband $\mathrm{X}$-rays and compare the results with those obtained previously from $\mathrm{eV}$ range $\mathrm{UV}$ irradiations. The differing energy deposition modes lead to clearly observable changes in the distributions of attachment products and their mechanisms of formation.

\section{MATERIALS AND METHODS}

\section{Materials}

Pyrene (Aldrich, 99\%) was recrystallized from benzene, passed through an alumina column using benzene as eluant, and recrystallized twice from ethanol to yield pale yellow crystals, mp $148.6-149.1^{\circ} \mathrm{C}$ (lit. (Perrin and Amarego 1988) mp $149-150^{\circ} \mathrm{C}$ ). Cyclohexane (EM Science, Reagent Grade) was washed with conc. $\mathrm{H}_{2} \mathrm{SO}_{4}$, passed through a short column of basic alumina, and then refluxed under a nitrogen atmosphere in the presence of $\mathrm{CaH}_{2}$ for 1 day. It was then distilled into a receiving flask containing freshly activated $5 \AA$ molecular sieves. C21 (Humphrey Chemical Company), $\mathrm{mp} 40-41^{\circ} \mathrm{C}$ (lit. (Sirota and Singer 1994) mp 40.14 C), was recrystallized three times from 95:5 acetone:hexane.
PREPARATION AND ANALYSIS OF PYRENE IN SOLID C21 AND LIQUID CYCLOHEXANE SOLUTIONS

Prior to bombardment, concentrations of pyrene in the liquid phases of $\mathbf{C 2 1}$ and cyclohexane were determined by UV-vis absorption spectra $(1 \mathrm{~mm}$ pathlength quartz cells) and Beer's law. Then, an aliquot of pyrene and solvent was transferred to a flattened glass capillary $(8 \mathrm{~mm}$ (i.d.) $\times 0.8 \mathrm{~mm}$ (i.d. $) \times 30$ $\mathrm{mm} ; 300 \mathrm{~nm}$ transmittance cutoff; Vitrocom) and flame-sealed after being degassed by four freezepump-thaw cycles at $<10^{-5}$ Torr on a mercury-free vacuum line.

Following bombardment, the cyclohexane and (heated, liquefied) C21 samples were dissolved in equivalent volumes of THF and analyzed by gel permeation chromatography (GPC) on a HewlettPackard Series 1100 ChemStation equipped with a diode array detector (4 $\mathrm{nm}$ bandwidth) using a Polymer Laboratories PLgel ( $3 \mu \mathrm{m}$ MIXED-E; 300 mm length $\times 7.5 \mathrm{~mm}$ ID) size exclusion column and tetrahydrofuran (THF; Fisher Scientific, HPLC grade) as the eluant.

\section{Broadband X-Ray Generation}

Broadband X-rays were generated by a $2.5 \mathrm{MeV}$ electron beam from a Febetron 705 on a thick tantalum converter operated at the Naval Surface Warfare Center (NSWC; Carderock Division, West Bethesda, MD). The mean energy of the continuous $\mathrm{X}$-ray photon spectrum was $<1.3>\mathrm{MeV}$. The width of the electron beam pulses was approximately $20 \mathrm{~ns}$ and the total dose given to each sample was $400 \mathrm{~Gy}$.

\section{RESULTS AND DISCUSSION}

X-RAY BOMBARDMENT OF PYRENE IN SOLID C21 AND LIQUID CYCLOHEXANE SOLUTIONS

In previous work, we have shown that the attachment of pyrene to several saturated alkanes, including solid C21 and liquid cyclohexane is very dependent on solvent phase, pyrene concentration, radiation wavelength, and alkane chain length when induced by UV-vis radiation (Zimerman and Weiss 1999). For instance, at $5 \times 10^{-6} \mathrm{M}$ pyrene, attach- 
ment in liquid $\mathbf{C 2 1}\left(>45^{\circ} \mathrm{C}\right)$ was much less efficient and selective than in its orthorhombic phase, below $32.5^{\circ} \mathrm{C}$ (Dorset et al. 1991). At higher pyrene concentrations, the efficiency of attachment to $\mathbf{C 2 1}$ in its orthorhombic phase decreased due to the formation of ground state aggregates.

As in the case with UV-vis irradiation, reaction efficiency of X-ray bombardment decreased with increasing pyrene concentration. However, X-ray bombardment of $10^{-5}$ or $10^{-2} \mathrm{M}$ pyrene in orthorhombic $\mathbf{C 2 1}$ led to the formation of both monoand di-alkylated pyrene products; the only photoproduct detected upon UV-vis irradiations was 1heneicosylpyrene (C21Py; eqn 1). The absorption spectra and retention volumes of the peaks labeled "M" and " $D$ " in the GPC chromatograms in Figures 1 and 2 are consistent with their structural assignments as mono- and di-heneicosylpyrenes. In addition to generating large concentrations of heneicosyl radicals at various positions along the alkane chain (via $\mathrm{C}-\mathrm{H}$ bond cleavage), $\mathrm{MeV}$ range $\mathrm{X}$-rays can cleave $\mathrm{C}-\mathrm{C}$ bonds, creating shortened chains terminated with radical centers (Wu et al. 2000). Each radical type can add (preferentially) to the 1position of pyrene (Mitchell et al. 1979), yielding an alkylpyrene after loss of a hydrogen atom (Lapouyade et al. 1986). The peak at $\sim 5.8 \mathrm{~min}$ is assigned to a dialkylated pyrene $(\mathbf{C 2 1 P y C 2 1}$; eqn 1). Its retention volume is smaller than those of mono-alkylated pyrenes and pyrene and its absorption spectrum is red-shifted by ca. $7 \mathrm{~nm}$ relative to those of mono-alkylated pyrenes (Figure 2). The absorption and emission spectra of pyrene analogues are known to shift incrementally to longer wavelengths as the number of alkyl substituents on the rings increases (De Clercq and Martin 1955).

Bombardment of $10^{-5} \mathrm{M}$ pyrene in liquid cyclohexane with $<1.3>\mathrm{MeV}$ X-rays yielded no products that could be ascribed to an alkylated pyrene, and only a very small amount of this product was detected when the pyrene concentration was increased to $10^{-2} \mathrm{M}$. A much lower efficiency in liquid (or plastic phase) cyclohexane than in solid heneicosane has also been observed when the attachment is ini- tiated by eV range photons (Zimerman and Weiss 1999). Regardless of the radiation type, the much greater ability of radicals to diffuse within liquid (or plastic) cyclohexane than in orthorhombic $\mathbf{C 2 1}$ is the probable reason for the lower efficiency.

The proposed mechanism of pyrene attachment using $\mathrm{eV}$ photons requires that an upper electronic excited state of pyrene transfer its energy to a nearby alkane molecule, inducing $\mathrm{C}-\mathrm{H}$ bond cleavage (Zimerman and Weiss 1999). For attachment to occur, a pyrene molecule and an alkane must be vicinal for a sufficient period after energy transfer to allow $\mathrm{C}-\mathrm{H}$ bond cleavage to occur and the resulting alkyl radical to attach itself to (the now ground-state) pyrene. In liquid cyclohexane, separation of the pair via diffusion is competitive with their attachment.

$\mathrm{MeV}$ broadband $\mathrm{X}$-rays and $\mathrm{eV}$ photons deposit their energy into hydrocarbon solutions of pyrene very differently. eV photons deposit energy initially into pyrene chromophores, creating electronically excited states of pyrene. Initially, $\mathrm{MeV}$ broadband $\mathrm{X}$-rays deposit their energy indiscriminately into alkane solutions; due to their much greater concentrations, the alkane solvent molecules receive a much greater portion of the energy than the pyrene solutes. Furthermore, the initial deposition of energy by ionizing radiation like X-rays creates local concentrations of high energy (i.e., single ionization spurs) within an alkane medium (Spinks and Woods 1964). Within spurs, processes such as electron ejection leads to hole formation and the generation of stable pyrene radical cations and anions which, upon recombination with electrons, form pyrene excited states (Biscoglio and Thomas 2000, Szadkowska-Nicze et al. 1992). The predominant processes within the spurs are $\mathrm{C}-\mathrm{H}$ and $\mathrm{C}-\mathrm{C}$ bond scissions that lead to the formation of lower molecular weight alkanes (Zagórski 2002) in addition to the attachment processes mentioned here. The radicals generated upon bond scission are located preferentially at the ends of $n$-alkane chains (Toriyama et al. 1982). In the solid phase of $\mathbf{C 2 1}$, the radical centers are near the interlayer interfaces where the pyrene molecules reside, and formation of henicosylpyrene 

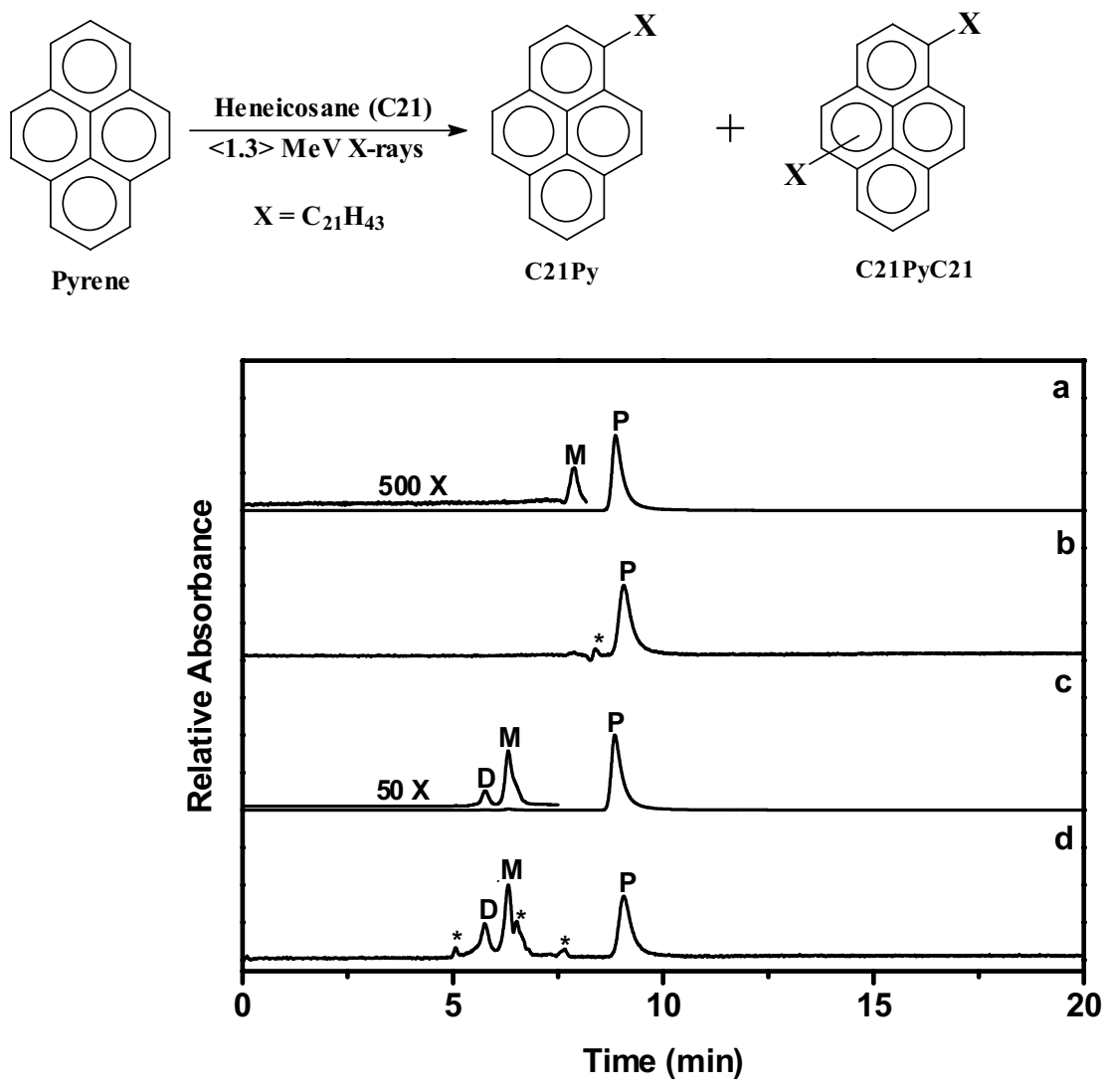

Fig. 1 - GPC chromatograms (THF; $\lambda_{\text {det }} 343 \mathrm{~nm}$ ) of degassed reaction mixtures of pyrene in liquid cyclohexane $\left(\mathrm{a}, 10^{-2} \mathrm{M} ; \mathrm{b}, 10^{-5} \mathrm{M}\right.$ ) and solid (orthorhombic) $\mathbf{C 2 1}$ (c, $10^{-2}$ $\mathrm{M} ; \mathrm{d}, 10^{-5} \mathrm{M}$ ) after bombardment with $<1.3>\mathrm{MeV}$ broadband $\mathrm{x}$-rays (dose $=400 \mathrm{~Gy}$ ) at room temperature. Peaks marked with $\mathrm{P}, \mathrm{M}$, and D correspond to unreacted pyrene, monosubstituted pyrene, and disubstituted pyrene, respectively. See Figure 2 for their UVvis absorption spectra. Peaks labeled with an asterisk were present in $\mathbf{C 2 1}$ and cyclohexane in the absence of pyrene; none has an absorption spectrum expected of a pyrenyl group.

is facilitated spatially.

\section{CONCLUSIONS}

We have shown that selective and relatively efficient attachment of pyrene to liquid cyclohexane and solid (orthorhombic phase) heneicosane can be attained via irradiation with $<1.3>\mathrm{MeV}$ broadband $\mathrm{x}$ rays. Irradiation of the pyrene/n-heneicosane samples yield both mono- and di-heneicosylpyrenes, whereas the only attachment product detected in liquid cyclohexane after the same dose is monosubstituted. In both cases, the reaction efficiency decreases when pyrene concentration is increased from $10^{-5}$ to $10^{-2} \mathrm{M}$. Qualitatively, the overall attachment efficiency is higher in orthorhombic $\mathbf{C 2 1}$ than in liquid cyclohexane, but the selectivity of attachment is greater in cyclohexane.

In liquid cyclohexane, selectivities of pyrene attachment initiated by irradiations with $\mathrm{UV} / \mathrm{vis}(\mathrm{eV}$ range) radiation or $\langle 1.3\rangle \mathrm{MeV} \mathrm{X}$-rays are similar. However, UV/vis and X-ray irradiations of pyrene in solid heneicosane follow rather different courses. The $\mathrm{eV}$ range photons initiate only mono-attachment while X-rays produce both mono- and di-substituted 


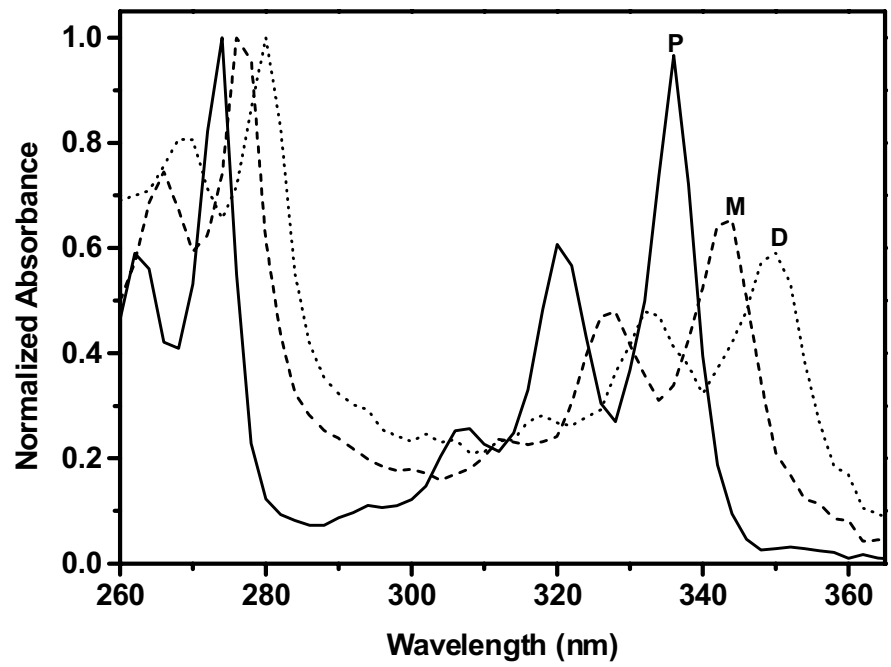

Fig. 2 - UV-vis absorption spectra of peaks in the GPC chromatogram of Figure 1c.

pyrenes. These results suggest that the density of alkane-based radicals generated by the broadband $\mathrm{X}$-rays around a pyrene molecule in $\mathbf{C 2 1}$ is much greater than by the UV/vis photons. Surprisingly, both forms of radiation lead to relatively selective photoreactions, even though the modes of initial energy deposition into the samples are very different.

\section{ACKNOWLEDGMENTS}

We are grateful to Mr. Jeff King from NSWC for performing the broadband $\mathrm{x}$-ray exposures and the U. S. National Science Foundation for financial support. This paper is dedicated to Professor Paschoal Senise, an institution in Brazilian science who built an Institute.

\section{RESUMO}

A exposição de $n$-heneicosano $\left(\mathrm{C}_{21} \mathrm{H}_{44}\right)$ dopado com pireno, em sua fase ortorrômbica sólida, a Raios X de faixa larga a $<1.3>\mathrm{MeV}$ resulta na formação de monoe di-heneicosilpirenos, enquanto que a mesma dose em ciclo-hexano líquido produz apenas pireno monossubstituído. Em ambos os casos, a eficiência da reação diminui quando a concentração de pireno aumenta de $10^{-5}$ a $10^{-2}$ M. Qualitativamente, a eficiência global de ligação é maior em $n$-heneicosano ortorrômbico do que em ciclohexano líquido, mas a seletividade de ligação é maior em ciclohexano. As diferenças entre estes resultados e os de irradiação das mesmas amostras com fotons na faixa de $\mathrm{eV}$ são discutidas.

Palavras-chave: raios $\mathrm{X}$ de faixa larga, pireno, ciclohexano, heneicosano.

\section{REFERENCES}

Biscoglio M and Thomas JK. 2000. Radiolysis of polyethylene films containing arenes: bromopyrene disssociation and pyrene binding in polymer films. J Phys Chem B 104: 475-484.

Brown GO, Guardala NA, Price JL and Weiss RG. 2002a. Selectivity and efficiency of pyrene attachment to polyethylene films by bombardment with MeV-range protons. J Phys Chem B 106: 3375-3382.

Brown GO, Guardala NA, Price JL and Weiss RG. 2002b. Comparison of energy deposition modes in polyethylene films by $\mathrm{MeV}$ range neutrons, electrons, protons, and alpha particles as monitored by covalent attachment of doped pyrene molecules. J Phys Chem B submitted.

Brown GO, Zimerman OE and Weiss RG. 2002c. The influence of molecular oxygen and the slip agent, erucamide, on the selectivity of attachment of pyrene to polyethylene chains by $>300 \mathrm{~nm}$ radiation. Polymer 43: 6495-6503. 
Caldwell RA, WhitTen DG ANd Hammond GS. 1966. Triplet states in radiation chemistry. Radiochemical cis-trans isomerization. J Am Chem Soc 88: 26592663.

de ClercQ M and Martin RH. 1955. Synthèses dans le domaine des hydrocarbures cancérigènes - XIV: Dérivés méthylés du pyrène. Bull Soc Chim Belg 64: 367-385.

Dorset DL, Strauss HL and SNyder RG. 1991. Chainlength dependence of the melting point differences between deuterated crystalline n-alkanes. J Phys Chem 91: 938-940.

Hammond GS, Caldwell RA, King JM, Kristinsson H, Whitten DG. 1968. Correlation between photochemistry and high-energy radiation chemistry. Photochem Photobiol 7: 695-703.

Lamotte M, Joussot-Dubien J, Lapouyade R and Pereyre J. 1985. Reactions following the excitation in upper excited states of pyrene and perylene in alkane solutions. In: LAhmani $F$ (Ed.), Photophysics and photochemistry above $6 \mathrm{eV}$, Amsterdam: Elsevier Science, p. 577-583.

Lamotte M, Pereyre J, Joussot-Dubien J and LAPOUYADE R. 1987. The photolysis of pyrene and perylene in cyclohexane liquid solution from highly excited electronic states. J Photochem 38: 177-188.

Lamotte M, Pereyre J, Lapouyade R and JoussotDuBIEN J. 1991. Multiphotonic photolysis of perylene and pyrene in liquid cyclohexane. J Photochem Photobiol A: Chem 58: 225-237.

Lapouyade R, Pereyre J and Garrigues P. 1986. Synthesis of the 3 monosubstituted pyrene and perylene regioisomers. CR Acad Sci II 303: 903-906.

Luo CP, Guardala NA, Price JL, Chodak I, Zimerman OE AND Weiss RG. 2002. Structural and dynamic investigations of unstretched and stretched ultrahigh molecular weight polyethylene films. 1-pyrenyl attachment by bombardment with $4.5 \mathrm{MeV}$ protons and irradiation with $\mathrm{eV}$ range photons. Macromolecules 35: 4690-4701.

Mitchell RH, Lai YH and Williams RV. 1979. NBromosuccinimide-dimethylformamide: a mild selective nuclear monobromination reagent for reactive aromatic compounds. J Org Chem 44: 4733-4735.
NACIRI J AND WeISS RG. 1989. New methods for the determination of dopant site distributions and dopant rates of diffusions in polymer films: emission from pyrenyl groups covalently attached to low-density polyethylene. Macromolecules 22: 3928-3936.

Penner TL, Whitten DG and Hammond GS. 1970. Radiation-induced reactions of 1,3-cyclohexadiene. J Am Chem Soc 92: 2861-2867.

PenNer TL and Hammond GS. 1971. Excited state formation in the irradiation of 1,3-cyclohexadiene. In: Horrocks DL and Peng CT (Eds.), Organic scintillation and liquid scintillation counting, proceedings of the international conference, New York: Academic Press, p. 327-337.

Perrin DD and Amarego WLF. 1988. Purification of laboratory chemicals, $3^{\text {rd }}$ ed., New York: Pergamon Press, p. 267.

Sirota EB ANd Singer DM. 1994. Phase transitions among the rotator phases of the normal alkanes. J Chem Phys 101: 10873-10882.

Sinks JWT and Woods RJ. 1964. An introduction to radiation chemistry, New York: Wiley, p. 70.

Szadkowska-Nicze M, Mayer J and Kroh J. 1992. Pulse radiolysis of solid polyethylene in the presence of pyrene. Radiat Phys Chem 39: 23-28.

ToRIYAMA K, IWASAKI M AND FuKaYa M. 1982. Evenodd alteration of the formation of chain end alkyl radicals in irradiated crystalline alkanes: ESR evidence. J Chem Soc Chem Commun 1293-1295.

Wu SM, Lin JJ, Lee YT, Yang X. 2000. Dynamics of atomic and molecular hydrogen from small alkanes following 157-nm excitation. J Phys Chem A 104: 7189-7199.

Yamaki SB, Atvars TDZ and Weiss RG. 2002. Selective attachment of pyrenyl groups to ethylene-covinyl acetate copolymers: dynamic and static fluorescence studies. Photochem Photobiol Sci 9: 649-655.

ZAGóRSKI ZP. 2002. Modification, degradation and stabilization of polymers in view of the classification of radiation spurs. Radiat Phys Chem 63: 9-19.

Zimerman OE and Weiss RG. 1999. Pyrene photochemistry in solid n-alkane matrices: comparisons with liquid-phase reactions. J Phys Chem A 103: 9794-9804. 